\title{
LEARNING FROM RECENT ADVANCES IN MEDICAL EDUCATION
}

\author{
McCahan, S; *Schreiber, M \\ Department of Mechanical \& Industrial Engineering, University of Toronto, Ontario Canada \\ mccahan@mie.utoronto.ca
}

\section{INTRODUCTION}

The history of engineering education shares some interesting features with the history of medical education which may give us some insight into future trends in engineering pedagogy. Both medicine and engineering have $19^{\text {th }}$ century roots in apprenticeships and were added to universities in North America later than some other professional programs, such as law. Also, both engineering and medicine have experienced a shift in pedagogical approach. First, from a practical, apprenticeship model to a much more theoretically based education grounded heavily in science. Then toward the end of the $20^{\text {th }}$ century both programs shifted back toward a more holistic, people centered, approach.

In addition to sharing a similar history of development, engineering and medicine are professional programs that are based in the application of science to solve problems. The curriculum tends to be a combination of courses that are heavy on content, and courses that allow the student to develop their skills through practice, such as design courses or clinical practice. Because of these shared attributes, engineering education has the opportunity to take advantage of the extensive research that exists on medical education.

\section{HISTORY}

Engineering education history is fairly well known to people who work in this field. After becoming a university program at the end of the $19^{\text {th }}$ century, the curriculum evolved toward a practical education that revolved around existing technologies. However, following the Grinter Report of $1955^{1}$ the curriculum shifted toward a highly science based approach.

Medical education took a similar but more direct path to a science centered university program. Medical education was substantially influenced by the Flexner Report of 1910 commissioned by the Carnegie Foundation $^{2}$ which advocated a science based curriculum. In addition, medical education became increasingly science driven with the explosion of knowledge in biochemistry, pharmacology, physiology, and genetics which occurred in the last century.

By the mid-1960's both engineering and medicine had reached a point where:

1. The curriculum was trying to keep up with knowledge base by packing in more and more information.

2. The educational model was creating many more specialists than before.

There were a number of impacts from this situation. First, engineers and doctors came to see situations from a specific technical viewpoint instead of holistically. Doctors tended to see the patient as a set of systems. The goal was to identify the specific problem and apply the science necessary to solve the problem. For engineers, their education revolved around technology. Public safety was important, but impact on society or the environment did not otherwise enter into their training. The result was a disconnect between these professions and the public, and a loss of public respect.

In medicine, political movements in the 1970's, such as the women's movement and the rise of alternative medicine, pushed doctors to reconsider their approach. Patients began to insist on being treated as whole human beings. This evolution resulted in some radical changes in the education system, such as the McMaster model which uses a primarily problem based learning (PBL) system. PBL is now used extensively in medical education across North America. Students consider the patient not as a set of isolated systems, but as an integrated, whole individual. Aspects of the patient's life outside of their immediate symptoms (nutrition, quality of relationships, etc.) are taken into account when treating the person. This also requires effective interaction between doctors and other health care and social care professionals.

In engineering the environmental movement, and other sociopolitical movements (such as rights for people with disabilities) pushed engineering to change. Engineers, partly through regulatory legislation, had to really begin to consider environmental impact. They had to design for a broader user group. And the public increasingly insisted that engineering be accountable not only for safety, but also for quality and usability of products, services, and infrastructure. This pressure was increased by global competition and global issues, such as the energy crisis. Another issue that drove a change in engineering education was the push for diversity in the profession, and a realization that many talented students were leaving engineering programs. As a result we saw a rise in the number of design courses, and courses oriented toward environmental impact in the 1980's. Engineering design, in particular, is now a central feature of many engineering programs. Modern design methods put the user at the center of the process. In many design courses we ask our students to consider not only the technical aspects of the design, but also the broader context in which the technology will be used including environmental impact.

\section{RECENT TRENDS}

Because of the similarities in these two professions, there are several recent trends in medical education that may be of interest to engineering educators. One is competency-based education. In this approach we carefully define what the practitioner needs to be able to do, and then work backwards to create a curriculum that will result in the development of these competencies. There is research in medical education on this subject that is relevant for engineers because in engineering we will need to use a system like this for the outcome based criteria that are coming into the fore in accreditation processes. ${ }^{3}$

Another area in which there is substantial research in medicine that is relevant for engineering is feedback models and methods. Researchers in medical education have studied the feedback process and have developed a number of methods particularly for giving effective feedback to students in clinical settings. ${ }^{4,5,6}$ These methods are highly transferable to assessment of students in project based courses, such as design courses. For example, Hewson and Little ${ }^{6}$ propose a model for a feedback cycle to help students develop an ability to more accurately self-assess their own performance. This is an essential competency for continuing professional development, i.e. life-long learning.

One of the other interesting trends in medical programs is interprofessional education (IPE). In IPE teams of students from multiple healthcare related disciplines (nursing, medicine, social work, etc.) team up to learn with, from and about each other via exercises such as PBL cases. $^{7}$ The idea is to acclimate medical students to talking and working with professionals from other fields with an eye toward developing more effective doctors. This method is used sparsely in engineering. There are occassionally courses that put engineering students in teams with archetects or industrial designers to tackle a project. However, it is clear that engineers in industry work extensively in interdisciplinary teams, not only with other types of engineers but with other types of professionals. It behoves us to examine the IPE method, and the educational research on this method, and consider whether we should be employing IPE as a planned part of our curricula.

\section{REFERENCES}

1. Grinter LE (chairman). Report on Evaluation of Engineering Education; Washington D.C.; 1955 June. American Association of Engineering Education.

2. Flexner A. Medical Education in the United States and Canada: A Report to the Carnegie Foundation for the Advancement of Teaching; New York City; 1910. The Carnegie Foundation for the Advancement of Teaching, Bulletin No. 4.

3. Albanese MA, Mejicano G, Mullan P, Kokotailo P, Gruppen L. Defining characteristics of educational competencies. Medical Education. 2008 Mar;42(3):248-55.

4. Ende J. Feedback in clinical medical education. JAMA. 1983 Aug 12;250(6):777-81.

5. Westberg J, Jason H. Fostering Reflection and Providing Feedback: Helping Others Learn from Experience. New York: Springer; 1991.

6. Hewson MG, Little ML. Giving Feedback in Medical Education. $J$ Intern Med. 1998;13(2):111-116.

7. Ho K, et al. Making interprofessional education work: the strategic roles of the academy. Acad Med. 2008 Oct;83(10):934-40.

AFFILIATED INSTITUTIONS FOR CO-AUTHORS

*Faculty of Medicine, University of Toronto, Ontario Canada 